\title{
Níveis de lisina digestível da ração e temperatura ambiente para frangos de corte em crescimento ${ }^{1}$
}

\author{
Jefferson Costa de Siqueira ${ }^{2}$, Rita Flávia Miranda de Oliveira ${ }^{3}$, Juarez Lopes Donzele ${ }^{3}$, Paulo \\ Roberto Cecon ${ }^{4}$, Eric Márcio Balbino ${ }^{5}$, Will Pereira de Oliveira ${ }^{5}$
}

\footnotetext{
${ }_{1}$ Parte da tese de Mestrado do primeiro autor.

2 Doutorando UNESP - Jaboticabal.

${ }^{3}$ Departamento de Zootecnia - UFV.

${ }^{4}$ Departamento de Informática - UFV.

${ }^{5}$ Mestrando - DZO/UFV.
}

RESUMO - Este estudo foi conduzido para avaliar os efeitos dos níveis de lisina digestível da ração e da temperatura ambiente sobre o desempenho e as características de carcaça de frangos de corte dos 22 a 42 dias de idade. Foram utilizados 672 frangos Ross ${ }^{\circledR}$, machos, com peso médio de $726 \mathrm{~g}$, em delineamento inteiramente casualizado segundo arranjo fatorial $4 \times 4$, com seis repetições de sete aves. Os frangos foram mantidos nas temperaturas de 18,$5 ; 21,1 ; 24,5$ e $27,0^{\circ} \mathrm{C}$ e foram alimentados com rações com diferentes níveis de lisina digestível (0,934; 1,009; 1,084 e 1,159\%). Não houve interação temperatura ambiente $\times$ níveis de lisina da ração para as variáveis estudadas. O consumo de ração (CR) e o ganho de peso (GP) não foram influenciados pelos níveis de lisina. O consumo de ração reduziu linearmente com a temperatura ambiente e o ganho de peso aumentou até a temperatura estimada de $21,5^{\circ} \mathrm{C}$. A conversão alimentar melhorou até o nível estimado de $1,085 \%$ de lisina digestível. Os pesos de carcaça (PC), peito com osso (PPO), coxa (PCX) e sobrecoxa (PSCX) aumentaram até as temperaturas estimadas de 21,9; 21,0; 22,7 e 23, $7^{\circ} \mathrm{C}$, respectivamente. Os rendimentos de carcaça (RC), coxa (RCX) e sobrecoxa (RSCX) aumentaram, enquanto o peso do peito sem osso (PPSO) e os rendimentos de peito com osso (RPO) e sem osso (RPSO) reduziram linearmente com a temperatura ambiente. O PCX e o RCX aumentaram, mas o RSCX reduziu linearmente com os níveis de lisina da ração. O PC, PPO, PSCX, RC, RPO e o RPSO não foram influenciados pelos níveis de lisina. A temperatura ambiente no intervalo de 18,5 e $27,0^{\circ} \mathrm{C}$ não influenciou as exigências de lisina das aves. A condição para melhor conversão alimentar no período de 22 a 42 dias foi obtida com o nível de 1,085\% de lisina digestível na ração e com a temperatura ambiente estimada de $23,3^{\circ} \mathrm{C}$.

Palavras-chave: ambiente térmico, aminoácidos, aves, desempenho, exigências nutricionais

\section{Dietary digestible lysine levels and environmental temperature for growing broiler chickens}

\begin{abstract}
This study was aimed to evaluate the effects of the dietary digestible lysine levels and environmental temperature on performance and carcass characteristics of broiler chickens from 22 to 42 days-old. Six hundred seventy two males Ross ${ }^{\circledR}$ broiler chickens with an average weight of 726 g were allotted to a completely randomized design, in a $4 \times 4$ factorial arrangement with six replicates and seven birds per experimental unit. The chickens were fed with different digestible lysine levels in the diet $(0.934,1.009,1.084$, and 1.159\%) and kept under different environmental temperatures (18.5, 21.1, 24.5, and $27.0^{\circ} \mathrm{C}$ ). There were no interactions between environmental temperature and lysine levels in the diet for the studied variables. Feed intake and the weight gain (WG) were not influenced by lysine levels in the diet. Feed intake linearly reduced with the environmental temperature and the WG increased up to the estimated temperature of $21.5^{\circ} \mathrm{C}$. The feed:gain ratio improved up to the estimated digestible lysine level in the diet of $1.085 \%$. The weights of carcass (CW), boned breast (BBW), thigh (TW) and drumstick (DW) increased up to the estimated temperatures of 21.9, 21.7, 22.7, and $23.7^{\circ} \mathrm{C}$, respectively. The yields of carcass (CY), thigh (TY) and drumstick (DY) increased, whereas the deboned breast weight (DBW), the boned breast yield (BBY) and deboned breast yield (DBY) linearly decreased with the environmental temperature. The TW and TY increased, whereas the DY linearly decreased with the lysine levels in the diet. The lysine levels did not influence the CW, $\mathrm{BBW}, \mathrm{DW}, \mathrm{CY}, \mathrm{BBY}$ and DBY. The environmental temperature in the range from 18.5 to $27.0^{\circ} \mathrm{C}$ did not influence the lysine requirements of the birds. The condition that provided better feed:gain ratio during the experimental period was obtained with the digestible lysine level in the diet of $1.085 \%$ and the estimated environmental temperature of $23.3^{\circ} \mathrm{C}$.
\end{abstract}

Key Words: amino acids, nutritional requirements, performance, poultry, thermal environment 


\section{Introdução}

O desenvolvimento de linhagens com alto potencial genético, associado ao contínuo desenvolvimento tecnológico nas áreas de nutrição, ambiência, sanidade e manejo, tem possibilitado a produção de alta quantidade de carne por unidade de área, além de redução progressiva no tempo de alojamento das aves. Nesse contexto, para que a produção de carne de qualidade seja otimizada, é necessário, entre outros fatores, o adequado e preciso suprimento de nutrientes, obtido por meio de rações balanceadas, formuladas de acordo com o potencial genético das aves e as condições ambientais de criação (Valerio et al., 2003).

Diversos autores (Baker \& Han, 1994; Rostagno et al., 1999; Costa et al., 2001; Ishibashi \& Yonemochi, 2002; Borges et al., 2002) têm relatado que os níveis ótimos de aminoácidos em rações para frangos de corte podem variar em razão de fatores como linhagem, idade, sexo, níveis nutricionais, fontes de energia e proteína, desafios imunológicos, manejo e temperatura ambiente.

A temperatura ambiente tem sido considerada importante no desempenho de frangos de corte, pois influencia o consumo de ração. Como os níveis nutricionais normalmente são expressos em porcentagem da ração (OviedoRondón \& Waldroup, 2002; Valerio et al., 2003), qualquer alteração no consumo tem conseqüências na ingestão dos nutrientes, podendo modificar o ganho de peso e a conversão alimentar e ainda os rendimentos de carcaça e cortes nobres.

Em estudos nutricionais utilizando rações à base de milho e farelo de soja, a lisina tem sido considerada o segundo aminoácido limitante para o crescimento e desenvolvimento de frangos de corte (Kidd et al., 1997; Costa et al., 2001; Ishibashi \& Yonemochi, 2002; Lana et al., 2005). Sabe-se também que a lisina é um aminoácido essencial cujo principal papel fisiológico é a síntese protéica (tecido muscular) e que está envolvida, em menores proporções, em outros processos metabólicos (Baker \& Han, 1994; Costa et al., 2001; Amarante Jr. et al., 2005; Takeara et al., 2005; Lana et al., 2005).

Considerando que as linhagens de frangos de corte modernas são caracterizadas pelo acelerado desenvolvimento corporal e pelo alto potencial de deposição de carne e que a deposição protéica tem alto custo energético, gerando grande quantidade de calor metabólico, é necessário que, nas atualizações dos padrões nutricionais, seja considerada a temperatura ambiente em que as aves são mantidas visando determinar níveis nutricionais adequados para as condições ambientais específicas de cada criação.
Este estudo foi realizado para avaliar o efeito do nível de lisina digestível da ração e da temperatura ambiente sobre o desempenho e as características de carcaça e de cortes nobres de frangos de corte machos em fase de crescimento (22 a 42 dias de idade).

\section{Material e Métodos}

O experimento foi conduzido no Laboratório de Bioclimatologia Animal do Departamento de Zootecnia, do Centro de Ciências Agrárias da Universidade Federal de Viçosa, em Viçosa, MG. Foram utilizados 672 frangos de corte machos, da linhagem Ross ${ }^{\circledR}$, vacinados contra as doenças de Marek e bouba aviária, mantidos durante o período de 22 a 42 dias de idade em câmaras climáticas com temperatura e umidade relativa do ar controladas. As câmaras climáticas foram ajustadas para manter temperaturas constantes de $18,21,24$ e $27^{\circ} \mathrm{C}$ e umidade relativa entre 65 e $75 \%$. Foram utilizados 168 frangos em cada temperatura.

Durante a fase inicial (1 a 21 dias de idade), as aves foram criadas em galpão convencional e alimentadas com ração com $3.000 \mathrm{kcal}$ de EM/kg e 21,8\% de PB, formulada para satisfazer suas exigências nutricionais, conforme preconizado por Rostagno et al. (2000).

No $22^{0}$ dia de idade, os frangos, pesando em média 726 g, foram transferidos para as câmaras climáticas, quando teve início o período experimental. As aves foram alojadas no interior das câmaras, em baterias com compartimentos $(0,85 \times 0,85 \mathrm{~m})$ providos de comedouro e bebedouro tipo calha. O experimento foi montado segundo arranjo fatorial $4 \times 4$ (quatro temperaturas e quatro níveis de lisina digestível), em delineamento inteiramente casualizado, com seis repetições, de modo que cada unidade experimental foi composta de sete aves.

As condições ambientais no interior das câmaras climáticas (Tabela 1 ) foram monitoradas e registradas diariamente, duas vezes ao dia (às 8 e $17 \mathrm{~h}$ ), por meio de termômetros (de bulbo seco, bulbo úmido e de globo negro) mantidos no centro das salas. Os dados foram convertidos em ITGU (Índice de Temperatura de Globo e Umidade), conforme proposto por Buffington et al. (1981). O programa de luz adotado durante o período experimental foi o contínuo (24 horas de luz artificial), obtido por meio de lâmpadas fluorescentes.

A ração basal, à base de milho e farelo de soja, foi formulada para atender às exigências nutricionais das aves, segundo recomendações de Rostagno et al. (2000), exceto em lisina. Essa ração foi suplementada com L-lisina $\mathrm{HCl}$ 78,5\% (0,000; 0,096; 0,193 e 0,290\%) em substituição ao 
amido de milho, resultando em rações experimentais isoprotéicas e isoenergéticas contendo 0,934; 1,009; 1,084 e 1,159\% de lisina digestível (Tabela 2).
Com o propósito de assegurar que nenhum outro aminoácido se tornasse limitante, as rações experimentais foram suplementadas com metionina + cistina, treonina,

Tabela 1 - Condições ambientais nas câmaras climáticas durante o período experimental

Table 1 - Environmental conditions in the climatic chambers during the experimental period

\begin{tabular}{|c|c|c|c|c|}
\hline \multirow[t]{2}{*}{ Item } & \multicolumn{4}{|c|}{$\begin{array}{l}\text { Câmara } \\
\text { Chamber }\end{array}$} \\
\hline & 1 & 2 & 3 & 4 \\
\hline Umidade relativa (\%) (Relative humidity) & $72,7 \pm 3,9$ & $68,3 \pm 6,9$ & $73,9 \pm 4,9$ & $64,2 \pm 6,8$ \\
\hline Índice de temperature de globo e umidade (Black globe humidity index) & $64,8 \pm 1,1$ & $69,2 \pm 1,3$ & $74,1 \pm 0,9$ & $75,6 \pm 1,0$ \\
\hline
\end{tabular}

Tabela 2 - Composições centesimal e calculada das rações experimentais

Table 2 - $\quad$ Percentage and calculated composition of experimental diets

\begin{tabular}{|c|c|c|c|c|}
\hline \multirow[t]{2}{*}{ Item } & \multicolumn{4}{|c|}{$\begin{array}{c}\text { Nível de lisina digestível (\%) } \\
\text { Digestible lysine level }\end{array}$} \\
\hline & 0,934 & 1,009 & 1,084 & 1,159 \\
\hline \multicolumn{5}{|l|}{$\begin{array}{l}\text { Ingrediente (\%) } \\
\text { Ingredient }\end{array}$} \\
\hline Milho (Corn) & 58,789 & 58,789 & 58,789 & 58,789 \\
\hline Farelo de soja (Soybean meal) & 33,640 & 33,640 & 33,640 & 33,640 \\
\hline Fosfato bicálcico (Dicalcium phosphate) & 1,595 & 1,595 & 1,595 & 1,595 \\
\hline Calcário (Limestone) & 0,919 & 0,919 & 0,919 & 0,919 \\
\hline Óleo vegetal (Soybean oil) & 3,200 & 3,200 & 3,200 & 3,200 \\
\hline Amido (Starch) & 1,000 & 0,845 & 0,631 & 0,341 \\
\hline Sal (Salt) & 0,382 & 0,382 & 0,382 & 0,382 \\
\hline Mistura vitamínica ${ }^{1}$ (Vitamin mix) & 0,100 & 0,100 & 0,100 & 0,100 \\
\hline Mistura mineral $^{2}$ (Mineral mix) & 0,050 & 0,050 & 0,050 & 0,050 \\
\hline Anticoccidiano $^{3}$ (Anticocidian) & 0,050 & 0,050 & 0,050 & 0,050 \\
\hline $\mathrm{BHT}^{4}$ & 0,010 & 0,010 & 0,010 & 0,010 \\
\hline Cloreto de colina $(60 \%)$ & 0,125 & 0,125 & 0,125 & 0,125 \\
\hline Avilamicina $(10 \%)^{5}$ (Avilamicine) & 0,007 & 0,007 & 0,007 & 0,007 \\
\hline DL-Met (99\%) & 0,133 & 0,188 & 0,244 & 0,299 \\
\hline L-Lys HCL $(78,5 \%)$ & 0,000 & 0,096 & 0,192 & 0,288 \\
\hline L-Val (99\%) & 0,000 & 0,004 & 0,065 & 0,126 \\
\hline L-Thr (99\%) & 0,000 & 0,000 & 0,000 & 0,004 \\
\hline L-Ile (99\%) & 0,000 & 0,000 & 0,000 & 0,041 \\
\hline L-Arg (99\%) & 0,000 & 0,000 & 0,000 & 0,032 \\
\hline \multicolumn{5}{|l|}{ Composição calculada (Calculated composition) } \\
\hline Proteína bruta (\%) (Crude protein) & 19,70 & 19,70 & 19,70 & 19,70 \\
\hline Energia metabolizável (kcal/kg) (Metabolizable energy) & 3.100 & 3.100 & 3.100 & 3.100 \\
\hline Lys digestível (\%) (Digestible Lys) & 0,934 & 1,009 & 1,084 & 1,159 \\
\hline Met + Cys digestível (\%) (Digestible met + cys) & 0,674 & 0,728 & 0,784 & 0,838 \\
\hline Thr digestível (\%) (Digestible Thr) & 0,645 & 0,645 & 0,645 & 0,660 \\
\hline Trp digestível (\%) (Digestible Trp) & 0,202 & 0,202 & 0,202 & 0,202 \\
\hline Val digestível (\%) (Digestible Val) & 0,808 & 0,811 & 0,872 & 0,932 \\
\hline Ile digestível (\%) (Digestible Ile) & 0,747 & 0,747 & 0,747 & 0,788 \\
\hline Arg digestível (\%) (Digestible Arg) & 1,237 & 1,237 & 1,237 & 1,268 \\
\hline Са $(\%)$ & 0,874 & 0,874 & 0,874 & 0,874 \\
\hline $\mathrm{Na}(\%)$ & 0,192 & 0,192 & 0,192 & 0,192 \\
\hline P disponível (\%) (Available P) & 0,406 & 0,406 & 0,406 & 0,406 \\
\hline
\end{tabular}

${ }^{1}$ Conteúdo/kg (Content/kg): vit. A - 15.000.000 UI; vit. D3 - 1.500 .000 Ul; vit. E - 15.000 UI; vit. B1 - 2,0 g; vit. B2 - 4,0 g; vit. B6 - 3,0 g; vit. B12 $0,015 \mathrm{~g}$; ácido nicotínico (Nicotinic acid) - $25 \mathrm{~g}$; ácido pantotênico (Pantothenic acid) - $10 \mathrm{~g}$; vit. K3 - 3,0 g; ácido fólico (Folic acid) - 1,0 g; bacitracina de zinco (Zinc bacitracine) - $10 \mathrm{~g}$; Se - $250 \mathrm{mg}$; antioxidante (Antioxidant) BHT - $10 \mathrm{~g}$; e veículo (Vehicle) q.s.p. - $1.000 \mathrm{~g}$.

2 Conteúdo/kg (Content/kg): Mn, $80 \mathrm{~g} ; \mathrm{Fe}, 80 \mathrm{~g} ; \mathrm{Zn}, 50 \mathrm{~g} ; \mathrm{Cu}, 10 \mathrm{~g} ; \mathrm{Co}, 2 \mathrm{~g} ; \mathrm{I}, 1 \mathrm{~g}$; e veículo (Vehicle) q.s.p. - $1.000 \mathrm{~g}$.

3 Salinomicina sódica - 60 ppm (Sodic salinomicine).

${ }^{4}$ Hidroxi-butil-tolueno (Beta Hidroxi Tolueno).

5 Surmax. 
triptofano, valina, isoleucina e arginina, conforme a necessidade, para evitar que suas relações com a lisina digestível ficassem abaixo daquelas preconizadas por Rostagno et al. (2000), na proteína ideal. Os comedouros e bebedouros foram reabastecidos duas vezes ao dia para possibilitar às aves livre acesso às rações experimentais e à água durante todo o período experimental.

Os valores de aminoácidos totais dos ingredientes, obtidos por meio de espectrometria por infravermelho proximal (NIRs), foram convertidos em aminoácidos digestíveis (Tabela 3) utilizando-se os coeficientes de digestibilidade das Tabelas Brasileiras para Aves e Suínos (2000).

As aves foram pesadas no início e ao final do período experimental para determinação do ganho de peso (GP). O consumo de ração (CR) foi calculado pela diferença entre o total de ração fornecido e as sobras dos comedouros e do piso dos compartimentos. Com base no CR e no GP, calculou-se a conversão alimentar (CA).

No final do período experimental (42ํㅜ dia), três aves de cada unidade experimental com peso próximo à média da unidade (10\% acima ou abaixo da média) foram abatidas após jejum alimentar de 12 horas. Depois de sangradas e depenadas, as aves foram evisceradas e as carcaças foram pesadas. O rendimento de carcaça foi calculado com base no peso vivo após jejum alimentar, enquanto os rendimentos dos cortes nobres foram obtidos com base no peso da carcaça eviscerada e depenada.

Tabela 3 - Valores de aminoácidos totais e digestíveis dos ingredientes das rações experimentais

Table 3 - Total and digestible amino acid values of the ingredients of experimental diets

\begin{tabular}{|c|c|c|c|c|}
\hline \multirow[t]{2}{*}{$\begin{array}{l}\text { Aminoácido } \\
\text { Amino acid }\end{array}$} & \multicolumn{2}{|c|}{$\begin{array}{l}\text { Milho } \\
\text { Corn }\end{array}$} & \multicolumn{2}{|c|}{$\begin{array}{l}\text { Farelo de soja } \\
\text { Soybean meal }\end{array}$} \\
\hline & $\mathrm{AAT}^{1}$ & $\mathrm{AAD}^{2}$ & $\mathrm{AAT}^{1}$ & $\mathrm{AAD}^{2}$ \\
\hline Lys & 0,215 & 0,174 & 2,770 & 2,473 \\
\hline Met + Cys & 0,330 & 0,289 & 1,274 & 1,108 \\
\hline Thr & 0,254 & 0,214 & 1,767 & 1,544 \\
\hline Ile & 0,219 & 0,200 & 2,082 & 1,872 \\
\hline Arg & 0,338 & 0,313 & 3,332 & 3,129 \\
\hline Val & 0,318 & 0,283 & 2,163 & 1,906 \\
\hline Trp & 0,057 & 0,049 & 0,615 & 0,516 \\
\hline Leu & 0,795 & 0,760 & 3,467 & 3,106 \\
\hline Phe & 0,326 & 0,304 & 2,325 & 2,108 \\
\hline His & 0,216 & 0,199 & 1,210 & 1,102 \\
\hline $\mathrm{PB}(C P)$ & \multicolumn{2}{|c|}{7,3} & \multicolumn{2}{|c|}{45,9} \\
\hline
\end{tabular}

1 Aminoácidos totais, determinados pelo Laboratório da Degussa - Animal Nutrition Service - São Paulo, SP (Total amino acid determined by Degussa Lab - Animal Nutrition Servicce-São Paulo).

2 Aminoácidos digestíveis, calculados com base nos coeficientes de digestibilidade descritos nas Tabelas Brasileiras para Aves e Suínos (2000) (Digestible amino acid calculated based in digestibility coefficients described in Tabelas Brasileiras Para Aves e Suínos, 2000).
Além das características de desempenho (CR, GP e CA) e do consumo de lisina digestível (CL), foram avaliados os pesos absolutos e os rendimentos de carcaça e dos cortes nobres (peito com osso, peito sem osso, coxa e sobrecoxa) das aves.

As análises estatísticas dos parâmetros avaliados foram realizadas utilizando-se o pacote computacional Sistema para Análises Estatísticas e Genéticas - SAEG (UFV, 2000). Os dados foram submetidos à análise de variância e, posteriormente, analisados pela metodologia da superfície de resposta, tendo como variáveis independentes o nível de lisina digestível da ração e a temperatura ambiente. Os modelos foram escolhidos com base na significância dos coeficientes de regressão, utilizando-se o teste t a 5\% de probabilidade e o coeficiente de determinação ( $\mathrm{R}^{2}$ = SQRegressão/SQTratamento).

\section{Resultados e Discussão}

Não ocorreu interação $(\mathrm{P}>0,05)$ níveis de lisina digestível da ração $\times$ temperatura ambiente para nenhuma das variáveis de desempenho estudadas, o que está de acordo com o observado por Mendes et al. (1997) e Martinez et al. (2002), que não verificaram interação níveis de lisina $\times$ temperatura ambiente quando avaliaram os efeitos dos níveis de lisina da ração sobre o desempenho de frangos de corte mantidos em diferentes temperaturas ambientes. Com esses resultados, evidenciou-se que as respostas aos níveis de lisina da ração não são influenciadas pela temperatura ambiente em frangos de corte na fase de crescimento.

$\mathrm{O}$ consumo de ração não foi influenciado $(\mathrm{P}>0,05)$ pelos níveis de lisina digestível da ração (Tabela 4), no entanto, apresentou redução linear $(\mathrm{P}<0,01)$ de 32,4 g para cada unidade de temperatura acrescida (Tabela 4). Estes resultados são semelhantes aos obtidos por Mendes et al. (1997) e Martinez et al. (2002), que, em estudo sobre os efeitos dos níveis de lisina em rações para frangos de corte mantidos em diferentes temperaturas, também não observaram variação no consumo em resposta aos níveis de lisina da ração, mas verificaram redução, com o aumento da temperatura ambiente.

A relação inversa entre a temperatura ambiente e o consumo de ração foi relatada por vários autores (Curtis, 1983; Suk \& Washburn, 1995; Rostagno, 1995; Mendes et al., 1997; Oliveira Neto et al., 2000). Esse padrão de variação no consumo de ração pelas aves em resposta ao ambiente térmico pode ser considerado um mecanismo termorregulatório, que resulta em diminuição ou aumento da produção de calor em aves mantidas em ambientes quentes ou frios, respectivamente. 
Tabela 4 - Desempenho e consumo de lisina digestível por frangos de corte no período de 22 a 42 dias de idade alimentados com diferentes níveis de lisina digestível nas rações e mantidos sob diferentes temperaturas ambientes

Table 4 - Performance and digestible lysine intake of 22 to $42 d$-old broiler chickens fed diets with different digestible lysine levels and kept under different environmental temperatures

\begin{tabular}{|c|c|c|c|c|c|}
\hline \multirow{3}{*}{$\begin{array}{l}\text { Nível de lisina } \\
\text { digestível (\%) } \\
\text { Digestible lysine }\end{array}$} & \multicolumn{4}{|c|}{$\begin{array}{l}\text { Temperatura } \\
\text { ambiente }\left({ }^{\circ} \mathrm{C}\right)\end{array}$} & \multirow[t]{3}{*}{ Média } \\
\hline & evel & \multicolumn{3}{|c|}{ Environmental temperature } & \\
\hline & 18,5 & 21,1 & 24,5 & 27,0 & \\
\hline \multicolumn{6}{|c|}{ Consumo de ração ${ }^{1}$ (g) (Feed intake) } \\
\hline 0,934 & 3.229 & 3.098 & 3.039 & 2.926 & 3.073 \\
\hline 1,009 & 3.079 & 3.175 & 2.878 & 2.913 & 3.011 \\
\hline 1,084 & 3.149 & 3.112 & 2.940 & 2.909 & 3.028 \\
\hline 1,159 & 3.215 & 3.032 & 2.958 & 2.874 & 3.020 \\
\hline Média (Mean) & 3.168 & 3.104 & 2.954 & 2.906 & \\
\hline CV (\%) & \multicolumn{4}{|c|}{3,70} & \\
\hline
\end{tabular}

Ganho de peso $^{2}$ (g/d) (Weight gain)

\begin{tabular}{llllll}
0,934 & 1.772 & 1.815 & 1.737 & 1651 & 1.744 \\
1,009 & 1.772 & 1.866 & 1.750 & 1699 & 1.772 \\
1,084 & 1.777 & 1.860 & 1.789 & 1685 & 1.778 \\
1,159 & 1.773 & 1.865 & 1.763 & 1689 & 1.773 \\
Média (Mean) & 1.774 & 1.852 & 1.760 & 1.681 & \\
CV (\%) & \multicolumn{5}{c}{3,38}
\end{tabular}

Consumo de lisina digestível ${ }^{3}$ (g/d) (Digestible lysine intake)

\begin{tabular}{llllll}
0,934 & 30,2 & 28,9 & 28,4 & 27,3 & 28,7 \\
1,009 & 31,1 & 32,0 & 29,0 & 29,4 & 30,4 \\
1,084 & 34,1 & 33,7 & 31,9 & 31,5 & 32,8 \\
1,159 & 37,3 & 35,1 & 34,3 & 33,3 & 35,0 \\
Média (Mean) & 33,1 & 32,5 & 30,9 & 30,5 & \\
CV (\%) & \multicolumn{7}{c}{3,67}
\end{tabular}

\begin{tabular}{lccccc}
\hline \multicolumn{5}{c}{ Conversão } & alimentar $^{4}$ (g/g) (Feed:gain ratio) \\
0,934 & 1,82 & 1,71 & 1,75 & 1,77 & 1,76 \\
1,009 & 1,74 & 1,70 & 1,65 & 1,72 & 1,70 \\
1,084 & 1,77 & 1,67 & 1,64 & 1,73 & 1,70 \\
1,159 & 1,81 & 1,63 & 1,68 & 1,70 & 1,71 \\
Média (Mean) & 1,79 & 1,68 & 1,68 & 1,73 \\
CV (\%) & \multicolumn{5}{c}{3,76} \\
\hline
\end{tabular}

${ }^{1}$ Consumo de ração (Feed intake) $=3768,96-32,4062 * * T\left(r^{2}=0,97\right)$.

${ }^{2}$ Ganho de peso (Weight gain) $=-496,503+216,443^{* *} T-5,04053^{* *} T^{2}$ $\left(R^{2}=0,90\right)$.

3 Consumo de lisina (Lysine intake) $=9,70733-0,340076^{* *} T+28,4201^{* *} \mathrm{~L}$ $\left(R^{2}=0,95\right)$.

4 Conversão alimentar (Feed:gain ratio) $=7,88705-0,23821^{\star *} \mathrm{~T}-6,39921^{\star *}$ $L+0,00510987^{* *} T^{2}+2,94766^{* *} L^{2}\left(R^{2}=0,78\right)$.

${ }^{* *}(P<0,01)$, teste $t(P<0.01, t$ test $)$.

Não houve efeito ( $\mathrm{P}>0,05)$ dos níveis de lisina digestível da ração sobre o ganho de peso, que, no entanto, foi influenciado de forma quadrática $(\mathrm{P}<0,01)$ pela temperatura ambiente e apresentou valor máximo de ganho de peso (1.827 g) na temperatura estimada de $21,5^{\circ} \mathrm{C}$ (Tabela 4). Este resultado está coerente com os relatos de Rostagno (1995) e Macari (2001) de que a faixa de conforto térmico para frangos de corte em crescimento é de 21 a $23^{\circ} \mathrm{C}$.

Os resultados obtidos neste estudo divergem daqueles verificados por diversos autores (Baker \& Han, 1994;
Conhalato et al., 1999; Costa et al., 2001; Valerio et al., 2001; Valerio et al., 2003; Borges et al., 2002; Takeara et al., 2005; Lana et al., 2005; Amarante Jr. et al., 2005), que constataram melhora no ganho de peso de frangos de corte em fase de crescimento em resposta a níveis crescentes de lisina na ração. A diferença nos resultados está relacionada, entre outros fatores, à utilização de diferentes ingredientes no preparo das rações experimentais, à variação do conteúdo de energia e aminoácidos e à utilização de diferentes linhagens de frangos de corte, além do delineamento experimental e dos métodos de análise dos dados utilizados.

O consumo de lisina das aves foi influenciado $(\mathrm{P}<0,01)$ de forma linear crescente pelos níveis de lisina digestível da ração e de forma linear decrescente pela temperatura ambiente (Tabela 4). Estes resultados podem ser justificados pelo fato de o nível de lisina digestível da ração não ter influenciado o consumo de ração, que, por sua vez, reduziu de forma linear à medida que a temperatura ambiente aumentou.

Foram observados efeitos $(\mathrm{P}<0,01)$ dos níveis de lisina da ração e da temperatura ambiente sobre a conversão alimentar das aves (Figura 1 ), que foi melhor $(1,64)$ no nível de lisina digestível estimado de $1,085 \%$ e na temperatura estimada de $23,3^{\circ} \mathrm{C}$. Esses resultados são similares aos obtidos por Lana et al. (2005), que, em pesquisa com frangos de corte mantidos em ambiente termoneutro $\left(23,8^{\circ} \mathrm{C}\right)$, estimaram em 1,075\% o nível de lisina digestível na ração que proporcionou melhor desempenho das aves no período de 22 a 42 dias de idade.

O valor estimado de 1,085\% de lisina digestível na ração foi superior ao recomendado por Rostagno et al. (2000), de $1,045 \%$ para frangos de 22 a 42 dias de idade, mas coerente com os encontrados em Rostagno et al. (2005), que preconizaram os níveis de 1,099 e 1,048\% de lisina digestível, respectivamente, para frangos de corte para as fases de 22 a 33 e 34 a 42 dias de idade.

Não houve interação $(\mathrm{P}>0,05)$ níveis de lisina digestível da ração $\times$ temperatura ambiente para nenhuma das características de carcaça e cortes nobres avaliados (Tabela 5). O peso e o rendimento de carcaça não foram influenciados $(\mathrm{P}>0,05)$ pelos níveis de lisina digestível da ração, no entanto, o peso de carcaça aumentou $(\mathrm{P}<0,01)$ de forma quadrática, com o ponto de máxima (1.981 g) ocorrendo na temperatura estimada de $21,9^{\circ} \mathrm{C}$. O rendimento de carcaça também aumentou, de forma linear $(\mathrm{P}<0,01)$, à medida que a temperatura ambiente aumentou (Tabela 5).

A melhoria no rendimento de carcaça em resposta ao aumento da temperatura ambiente pode ser justificada pelo fato de que frangos de cortes mantidos em temperaturas acima da faixa de conforto térmico têm o tamanho dos 


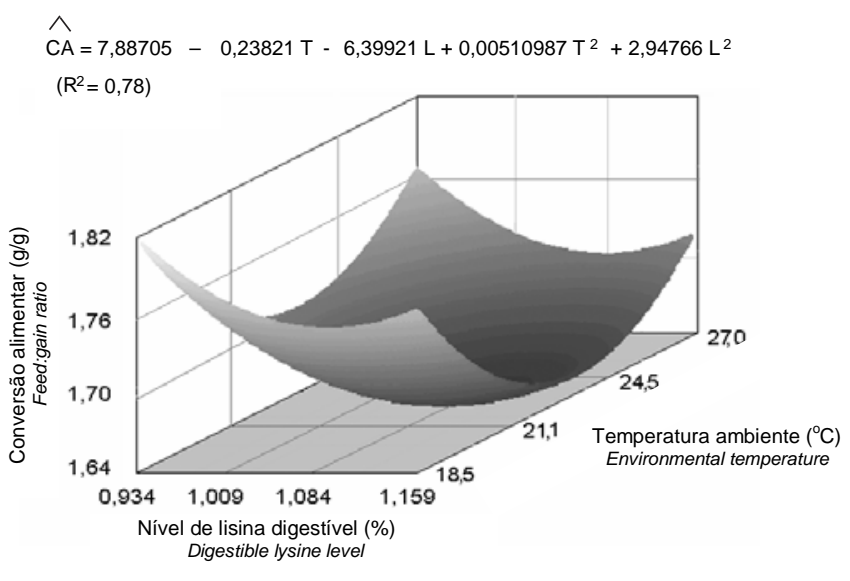

Figura 1 - Conversão alimentar em frangos de corte dos 22 aos 42 dias de idade alimentados com diferentes níveis de lisina digestível nas rações e mantidos sob diferentes temperaturas ambientais.

Figure 1 - Feed:gain ratio of 22 to $42 d$-old broiler chickens fed diets with different digestible lysine levels and kept under different environmental temperatures.

órgãos reduzido, culminando com o aumento da relação entre peso da carcaça eviscerada e peso das aves em jejum (Lana et al., 2000; Oliveira et al., 2006).

Os efeitos dos níveis de lisina nas características de carcaça foram semelhantes aos obtidos por Mendes et al. (1997) e Martinez et al. (2002), que também não observaram influência do nível de lisina da ração sobre as características de carcaça de frangos submetidos a diferentes temperaturas e alimentados com rações com diferentes níveis de lisina. Do mesmo modo, Conhalato et al. (1999), Valerio et al. (2003) e Amarante Jr. et al. (2005) não verificaram efeitos significativos dos níveis de lisina da ração sobre os pesos absolutos e os rendimentos de carcaça de frangos de corte no período de 22 a 42 dias de idade.

Esses resultados divergem dos obtidos por Costa et al. (2001), Borges et al. (2002) e Takeara et al. (2005), que observaram, respectivamente, aumento linear no rendimento e no peso de carcaça quando avaliaram os efeitos dos níveis de lisina da ração sobre as características de carcaça de frangos de corte em fase de crescimento.

Neste estudo, não houve efeito $(\mathrm{P}>0,05)$ dos níveis de lisina digestível da ração sobre o peso e o rendimento de peito com osso (PPO e RPO, respectivamente). A temperatura ambiente, no entanto, influenciou $(\mathrm{P}<0,01)$ o $\mathrm{PPO}$, que aumentou de forma quadrática até a temperatura estimada de $21,0^{\circ} \mathrm{C}$, com o valor máximo de PPO estimado em 629 g. O rendimento de peito com osso também foi influenciado pela temperatura ambiente reduzindo de forma linear $(\mathrm{P}<0,01)$ em $0,1268 \%$ para cada unidade de temperatura (Tabela 5).
Os níveis de lisina digestível da ração também não influenciaram $(\mathrm{P}>0,05)$ o peso e o rendimento de peito sem osso (PPSO e RPSO, respectivamente) das aves mantidas nas diferentes temperaturas. No entanto, a temperatura ambiente influenciou $(\mathrm{P}<0,01)$ o PPSO e o RPSO, que reduziram de forma linear (Tabela 5 ).

A temperatura estimada de $21,0^{\circ} \mathrm{C}$ para proporcionar máximo $\mathrm{PPO}$ foi próxima às estimadas para maximizar o $\mathrm{GP}$ $\left(21,5^{\circ} \mathrm{C}\right)$ e o $\mathrm{PC}\left(21,9^{\circ} \mathrm{C}\right)$, confirmando que a faixa de termoneutralidade para frangos de corte dos 22 aos 42 dias de idade possivelmente corresponde a $20,0-23,0^{\circ} \mathrm{C}$, conforme proposto por Rostagno (1995) e Macari (2001).

As reduções no RPO, PPSO e no RPSO podem estar relacionadas ao possível aumento gradativo dos níveis de corticosterona no plasma das aves, como conseqüência da elevação da temperatura ambiente. De acordo com os estudos de Yunianto et al. (1997), à medida que a temperatura ambiente se afasta da zona de conforto térmico, as concentrações plasmáticas de corticosterona aumentam progressivamente, denotando correlação positiva entre os níveis plasmáticos de corticosterona e a taxa de degradação de proteínas musculares.

Os resultados obtidos para os efeitos dos níveis de lisina digestível da ração corroboram trabalhos de diversos autores (Mendes et al., 1997; Conhalato et al., 1999; Martinez et al., 2002; Amarante Jr. et al., 2005), que também não notaram efeito dos níveis de lisina sobre o peso e o rendimento de peito em frangos na fase de crescimento. No entanto, contrastam com os observados por Costa et al. (2001), Borges et al. (2002), Valerio et al. (2003), Takeara et al. (2005) e Lana et al. (2005), que verificaram melhora no peso e/ou no rendimento de peito de frangos de corte em fase de crescimento com o aumento do nível de lisina da ração.

Foram observados efeitos da temperatura ambiente $(\mathrm{P}<0,01)$ e dos níveis de lisina digestível $(\mathrm{P}<0,05)$ sobre o peso de coxa (PCX) das aves, que aumentou de forma quadrática até a temperatura estimada de $22,7^{\circ} \mathrm{C}$, quando se fixou o nível de lisina da ração, e de forma linear de acordo com os níveis de lisina digestível da ração, quando se fixou a temperatura ambiente (Tabela 5).

A temperatura ambiente $(\mathrm{P}<0,05)$ e o nível de lisina digestível $(\mathrm{P}<0,01)$ da ração tiveram efeito linear crescente sobre o rendimento de coxa (RCX) das aves (Tabela 5).

Considerando esse resultado e o de RPSO e que a musculatura do peito de frangos de cortes é composta predominantemente por fibras glicolíticas (Tipo IIb) de contração rápida, enquanto a musculatura da perna é formada predominantemente por fibras oxidativas de contração lenta (Tipo I) (Faria Filho et al., 2003; Sartori et al., 2003), 
Tabela 5 - Características de carcaça e de cortes nobres de frangos de corte no período de 22 a 42 dias de idade alimentados com diferentes níveis de lisina digestível nas rações e mantidos sob diferentes temperaturas ambientais

Table 5 - Characteristics of carcass and edible cuts of 22 to $42 d$-old broiler chickens fed diets with different digestible lysine levels and kept under different environmental temperatures

\begin{tabular}{|c|c|c|c|c|c|}
\hline \multirow{3}{*}{$\begin{array}{l}\text { Nível de lisina } \\
\text { digestível (\%) } \\
\text { Digestible lysine }\end{array}$} & & $\begin{array}{l}\text { Temp } \\
\text { ambi }\end{array}$ & $\begin{array}{l}\text { atura } \\
\text { e }\left({ }^{\circ} \mathrm{C}\right)\end{array}$ & & \multirow[t]{3}{*}{$\begin{array}{l}\text { Média } \\
\text { Mean }\end{array}$} \\
\hline & level & \multicolumn{3}{|c|}{ Environmental temperature } & \\
\hline & 18,5 & 21,1 & 24,5 & 27,0 & \\
\hline \multicolumn{6}{|c|}{ Peso de $\operatorname{carcaça}^{1}(\mathrm{~g})$ (Carcass weight) } \\
\hline 0,934 & 1.925 & 1.976 & 1.953 & 1.919 & 1.943 \\
\hline 1,009 & 1.962 & 2.004 & 1.916 & 1.920 & 1.951 \\
\hline 1,084 & 1.922 & 1.986 & 1.966 & 1.880 & 1.939 \\
\hline 1,159 & 1.951 & 2.016 & 1.956 & 1.916 & 1.960 \\
\hline Média (Mean) & 1.940 & 1.996 & 1.948 & 1.909 & \\
\hline CV $(\%)$ & & & & & \\
\hline \multicolumn{6}{|l|}{$\operatorname{CV}(\%)$} \\
\hline 0,934 & 80,92 & 81,28 & 81,81 & 82,70 & 81,67 \\
\hline 1,009 & 80,81 & 81,05 & 81,78 & 82,42 & 81,52 \\
\hline 1,084 & 80,65 & 80,93 & 81,21 & 81,44 & 81,06 \\
\hline 1,159 & 80,93 & 80,94 & 81,71 & 81,71 & 81,57 \\
\hline Média (Mean) & 80,83 & 81,30 & 81,63 & 82,07 & \\
\hline CV (\%) & \multicolumn{5}{|c|}{1,65} \\
\hline
\end{tabular}

Peso de peito com osso ${ }^{3}$ (g) (Boned breast weight)

\begin{tabular}{llllll}
0,934 & 606 & 631 & 613 & 596 & 612 \\
1,009 & 635 & 634 & 597 & 604 & 618 \\
1,084 & 618 & 646 & 610 & 590 & 616 \\
1,159 & 617 & 643 & 617 & 599 & 619 \\
Média (Mean) & 619 & 639 & 609 & 597 & \\
CV (\%) & \multicolumn{5}{c}{7,17} \\
\hline
\end{tabular}

\begin{tabular}{lrrrrr}
\hline \multicolumn{7}{c}{ Rendimento de peito com osso $^{4}$ (\%) } & (Boned breast yield) \\
0,934 & 31,70 & 31,88 & 31,28 & 30,84 & 31,43 \\
1,009 & 32,49 & 31,70 & 31,14 & 31,20 & 31,63 \\
1,084 & 32,36 & 32,36 & 31,05 & 31,27 & 31,76 \\
1,159 & 31,89 & 31,90 & 31,51 & 31,33 & 31,66 \\
Média (Mean) & 32,11 & 31,96 & 31,24 & 31,16 & \\
CV (\%) & \multicolumn{6}{c}{4,36} \\
\hline
\end{tabular}

\begin{tabular}{lccccc}
\hline \multicolumn{7}{c}{ Peso de peito sem osso $^{5}$ (g) (Deboned Breast weight) } \\
0,934 & 455 & 472 & 453 & 441 & 455 \\
1,009 & 489 & 469 & 448 & 448 & 464 \\
1,084 & 470 & 486 & 455 & 440 & 463 \\
1,159 & 463 & 480 & 460 & 444 & 462 \\
Média (Mean) & 469 & 477 & 454 & 443 & \\
CV (\%) & \multicolumn{7}{c}{9,14} \\
\hline
\end{tabular}

Continua na próxima coluna...

pode-se inferir que o efeito da temperatura ambiente sobre os músculos da carcaça de aves pode variar de acordo com o tipo de fibras musculares que os compõem.

Esse efeito diferenciado da temperatura ambiente sobre os músculos da carcaça estaria, possivelmente, relacionado à ação do hormônio corticosterona, cuja concentração
Rendimento de peito sem osso ${ }^{6}$ (\%) (Deboned breast yield)

\begin{tabular}{llllll}
0,934 & 23,78 & 23,86 & 23,07 & 22,86 & 23,49 \\
1,009 & 24,98 & 23,42 & 23,34 & 23,17 & 23,73 \\
1,084 & 24,59 & 24,28 & 23,17 & 23,29 & 23,83 \\
1,159 & 23,95 & 23,79 & 23,49 & 23,22 & 23,61 \\
Média (Mean) & 24,33 & 23,84 & 23,27 & 23,14 & \\
CV (\%) & \multicolumn{5}{c}{6,35} \\
\hline
\end{tabular}

\begin{tabular}{llllll}
\hline \multicolumn{5}{c}{ Peso de coxa $^{7}$ (g) (Thigh weight) } \\
0,934 & 244 & 251 & 252 & 250 & 249 \\
1,009 & 250 & 260 & 250 & 252 & 253 \\
1,084 & 244 & 254 & 251 & 242 & 248 \\
1,159 & 255 & 265 & 258 & 254 & 258 \\
Média (Mean) & 248 & 258 & 253 & 250 & \\
CV(\%) & \multicolumn{5}{c}{6,73} \\
\hline
\end{tabular}

\begin{tabular}{lccccc}
\hline \multicolumn{6}{c}{ Rendimento de $\operatorname{coxa}^{8}$ (\%) (Thigh yield) } \\
0,934 & 12,79 & 12,71 & 12,93 & 12,97 & 12,78 \\
1,009 & 12,74 & 12,98 & 13,06 & 13,13 & 12,98 \\
1,084 & 12,82 & 12,77 & 12,81 & 12,83 & 12,81 \\
1,159 & 13,18 & 13,07 & 13,19 & 13,23 & 13,17 \\
Média (Mean) & 12,88 & 12,88 & 13,00 & 13,04 \\
CV (\%) & Peso de & sobrecoxa & \\
\hline \multicolumn{7}{c}{ (g) } & (Drumstick weight) \\
0,934 & 241 & 258 & 253 & 265 & 254 \\
1,009 & 246 & 254 & 251 & 251 & 251 \\
1,084 & 241 & 248 & 256 & 249 & 249 \\
1,159 & 238 & 255 & 259 & 242 & 249 \\
Média (Mean) & 242 & 254 & 255 & 252 & \\
CV (\%) & \multicolumn{7}{c}{9,31} \\
\hline
\end{tabular}

\begin{tabular}{|c|c|c|c|c|c|}
\hline \multicolumn{6}{|c|}{ Rendimento de sobrecoxa ${ }^{10}$ (\%) (Drumstick yield) } \\
\hline 0,934 & 12,62 & 13,11 & 12,97 & 13,68 & 13,10 \\
\hline 1,009 & 12,56 & 12,68 & 13,11 & 13,10 & 12,86 \\
\hline 1,084 & 12,67 & 12,44 & 13,05 & 13,20 & 12,84 \\
\hline 1,159 & 12,29 & 12,56 & 13,25 & 12,62 & 12,68 \\
\hline Média (Mean) & 12,54 & 12,70 & 13,10 & 13,15 & \\
\hline \multicolumn{3}{|l|}{$\mathrm{CV}(\%)$} & \multicolumn{3}{|c|}{7,52} \\
\hline \multicolumn{6}{|c|}{$\begin{array}{l}1 \text { Peso de carcaça (Carcass weight) }=553,904+130,383^{\star \star} T-2,97754^{\star \star} T^{2} \\
\left(R^{2}=0,82\right) \text {. }\end{array}$} \\
\hline \multicolumn{6}{|c|}{ Rendimento de $\operatorname{carcaca}(C$} \\
\hline \multicolumn{6}{|c|}{ Peso de peito com osso (Breast weight with bone) $=194,379+41,4434^{* *}$} \\
\hline \multicolumn{6}{|c|}{$\begin{array}{l}4 \text { Rendimento de peito com osso (Breast yield with bone) }=34,5049-0,126771^{\star \star} \\
T\left(r^{2}=0,94\right) \text {. }\end{array}$} \\
\hline \multicolumn{6}{|l|}{5 Peso de peit } \\
\hline \multicolumn{6}{|l|}{6 Rendimento } \\
\hline \multicolumn{6}{|c|}{$\begin{array}{l}7 \text { Peso de coxa (Thigh weight) } \\
0,404788^{\star *} T^{2}\left(R^{2}=0,46\right) \text {. }\end{array}$} \\
\hline \multicolumn{6}{|c|}{$\begin{array}{l}8 \text { Rendimento de coxa }(\text { Thigh yield })=11,3561+0,0219009^{*} T+1,0557^{* *} L \\
\left(R^{2}=0,47\right) \text {. }\end{array}$} \\
\hline \multicolumn{6}{|c|}{$\begin{array}{l}9 \text { Peso de sobre coxa (Drumstick weight) }=-39,4266+24,9194^{\star *} T \text { - } \\
0,525196^{\star *} T^{2}\left(R^{2}=0,97\right) \text {. }\end{array}$} \\
\hline \multicolumn{6}{|c|}{ * $(P<0,01)$, teste $t(P<0.01, t$ test $)$} \\
\hline
\end{tabular}

plasmática nas aves eleva à medida que a temperatura ambiente ultrapassa a faixa de termoneutralidade. De acordo com os resultados obtidos por Silva (2002) em estudos conduzidos com mamíferos, os efeitos catabólicos dos hormônios esteróides (corticosterona) nas fibras glicolíticas são mais pronunciados que nas fibras oxidativas. 
O peso de sobrecoxa (PSCX), que não variou ( $\mathrm{P}>0,05)$ com os níveis de lisina digestível, foi influenciado pela temperatura ambiente tendo aumentado de forma quadrática $\left(\mathrm{P}<0,01\right.$ ) até a temperatura estimada de $23,7^{\circ} \mathrm{C}$ (Tabela 5).

A ausência de efeito dos níveis de lisina da ração sobre o PSCX de frangos de corte confirma os resultados obtidos por Valerio et al. (2003), que também não verificaram efeitos dos níveis de lisina digestível sobre o PSCX de frangos mantidos a $29,1^{\circ} \mathrm{C}$ no período de 22 a 42 dias de idade. No entanto, divergem dos obtidos por Borges et al. (2002) e Lana et al. (2005), que observaram melhora no PSCX com o aumento dos níveis de lisina da ração em pesquisa com frangos de corte dos 22 aos 42 dias de idade mantidos em ambiente com 26,0 e $23,8^{\circ} \mathrm{C}$, respectivamente.

O rendimento de sobrecoxa (RSCX) foi influenciado de forma linear crescente $(\mathrm{P}<0,01)$ pela temperatura ambiente e de forma linear decrescente $(\mathrm{P}<0,05)$ pelos níveis de lisina digestível da ração (Tabela 5). O efeito positivo da temperatura ambiente sobre o RSCX foi semelhante ao observado para o RCX e pode ser justificado pela redução nos valores das variáveis relacionadas ao peito (RPO, PPSO e RPSO) à medida que a temperatura ambiente aumentou, 0 que resultou em aumento da proporção de sobrecoxa em relação à carcaça inteira.

A redução no RSCX com o aumento dos níveis de lisina da ração pode ser justificada por meio da análise conjunta do PCX e do PSCX, tomando-se como referência a ausência de efeitos dos níveis de lisina sobre o peso da perna das aves.

\section{Conclusões}

As exigências de lisina digestível de frangos de corte em fase de crescimento não foram influenciadas pela temperatura ambiente de 18,5 a $27,0^{\circ} \mathrm{C}$.

A condição ótima para minimizar a conversão alimentar (1,64 g/g) de frangos de corte no período de 22 a 42 dias de idade foi obtida com o nível estimado de 1,085\% de lisina digestível e com a temperatura estimada de $23,3^{\circ} \mathrm{C}$. O nível de lisina digestível de 1,085\% na ração foi adequado para a melhor conversão alimentar de frangos de corte mantidos em temperatura ambiente de 18,5 a $27,0^{\circ} \mathrm{C}$ no período de 22 a 42 dias de idade. A faixa de conforto térmico para frangos de corte no período de 22 a 42 dias de idade é de 21,0 a $23,7^{\circ} \mathrm{C}$.

\section{Literatura Citada}

AMARANTE JR., V.S.; COSTA, F.G.P.; BARROS, L.R. et al. Níveis de lisina para frangos de corte nos períodos de 22 a 42 e de 43 a 49 dias de idade, mantendo a relação metionina + cistina. Revista Brasileira de Zootecnia, v.34, p.1188-1194, 2005.
BAKER, D.H.; HAN, Y. Ideal amino acid profile for chickens during the first three weeks posthatching. Poultry Science, v.73, p.1441-1447, 1994.

BORGES, A.F.; OLIVEIRA, R.F.M.; DONZELE, J.L. et al. Exigência de lisina para frangos de corte machos no período de 22 a 42 dias de idade mantidos em ambiente quente $\left(26^{\circ} \mathrm{C}\right)$. Revista Brasileira de Zootecnia, v.31, p.1993-2002, 2002.

BUFFINGTON, D.E.; COLAZZO-AROCHO, A.; CANTON, G.H. et al. Black globe-humidity index (BGHI) as comfort equation for dairy cows. Transaction of the ASAE, v.24, p.711-714, 1981.

CONHALATO, G.S.; DONZELE, J.L.; ALBINO, L.F.T. et al. Níveis de lisina digestível para frangos de corte machos na fase de 22 a 42 dias de idade. Revista Brasileira de Zootecnia, v.28, p.98-104, 1999.

COSTA, F.G.P.; ROSTAGNO, H.S.; ALBINO, L.F.T. et al. Níveis dietéticos de lisina para frangos de corte de 1 a 21 e 22 a 40 dias de idade. Revista Brasileira de Zootecnia, v.30, p.14901497, 2001.

CURTIS, S.E. Environmental management in animal agriculture. Ames: Iowa State University Press, 1983. 410p.

FARIA FILHO, D.E.; RIZZO, M.F.; WADA, M.T. et al. Rendimento de carcaça, de cortes comerciais e deposição de gordura abdominal em frangos recebendo dietas de baixa proteína e criados em diferentes temperaturas ambiente. In: REUNIÃO ANUAL DA SOCIEDADE BRASILEIRA DE ZOOTECNIA, 40., 2003, Santa Maria. Anais... Santa Maria: Sociedade Brasileira de Zootecnia, 2003. (CD-ROM).

ISHIBASHI, T.; YONEMOCHI, C. Possibility of amino acid nutrition in broiler. Journal of Animal Science, v.73, p.155165, 2002.

KIDD, M.T.; KERR, B.J.; ANTHONY, N.B. Dietary interactions between lysine and threonine in broilers. Poultry Science, v.76, p.608-614, 1997.

LANA, G.R.Q.; ROSTAGNO, H.S.; ALBINO, L.F. et al. Efeito da temperatura ambiente e da restrição alimentar sobre o desempenho e a composição de carcaça de frangos de corte. Revista Brasileira de Zootecnia, v.29, p.1117-1123, 2000.

LANA, S.R.V.; OLIVEIRA, R.F.M.; DONZELE, J.L. et al. Níveis de lisina digestível em rações para frangos de corte de 22 a 42 dias de idade, mantidos em ambiente de termoneutralidade. Revista Brasileira de Zootecnia, v.34, p.1624-1632, 2005.

MACARI, M. Estresse de calor em aves. In: REUNIÃO ANUAL DA SOCIEDADE BRASILEIRA DE ZOOTECNIA, 38., 2001, Piracicaba. Anais... Piracicaba: Fundação de Estudos Agrários “Luiz de Queiroz”, 2001. p.686-716.

MARTINEZ, K.L.A.; PEZZATO, A.C.; GONÇALVES, J.C. et al. Níveis de lisina em rações formuladas a partir de aminoácidos totais e digestíveis para frangos de corte submetidos a diferentes temperaturas. In: REUNIÃO ANUAL DA SOCIEDADE BRASILEIRA DE ZOOTECNIA, 39., 2002 Recife. Anais.. Recife: Sociedade Brasileira de Zootecnia, 2002. (CD-ROM).

MENDES, A.A.; WATKINS, S.E.; ENGLAND, J.A. et al. Influence of dietary lysine level and arginine: lysine rations on performance of broilers exposit to heat or cold stress during the period of three to six weeks of age. Poultry Science, v.76, p.472-481, 1997.

OLIVEIRA NETO, A.R.; OLIVEIRA, R.F.M.; DONZELE, J.L. et al. Efeito da temperatura ambiente sobre o desempenho e características de carcaça de frangos de corte alimentados com dieta controlada e dois níveis de energia metabolizável Revista Brasileira de Zootecnia, v.29, p.183-190, 2000.

OLIVEIRA, G.A.; OLIVEIRA, R.F.M.; DONZELE, J.L. et al. Efeito da temperatura ambiente sobre o desempenho e as características de carcaça de frangos de corte dos 22 aos 42 dias. Revista Brasileira de Zootecnia, v.35, p.1398-1405, 2006.

OVIEDO-RONDÓN, E.O.; WALDROUP, P.W. Models to estimate amino acid requirements for broiler chickens: a review. International Journal of Poultry Science, v.5, p.106-113, 2002. 
ROSTAGNO, H.S. Programas de alimentação e nutrição para frangos de corte adequados ao clima. In: CONFERÊNCIA APINCO, SIMPÓSIO INTERNACIONAL SOBRE AMBIÊNCIA E INSTALAÇÕES NA AVICULTURA INDUSTRIAL, 1995, Campinas. Anais... Campinas: Fundação Apinco de Ciência e Tecnologia Avícola, 1995. p.11-19.

ROSTAGnO, H.S.; ALBINO, L.F.T.; DONZELE, J.L. et al. Tabelas brasileiras para aves e suínos: composição de alimentos e exigências nutricionais. Viçosa, MG: Universidade Federal de Viçosa, 2000. 141p.

ROSTAGNO, H.S.; ALBINO, L. F.T.; DONZELE, J.L. et al. Tabelas brasileiras para aves e suínos: composição de alimentos e exigências nutricionais. 2.ed. Viçosa, MG: Editora UFV, Departamento de Zootecnia, 2005. 186p.

ROSTAGNO, H.S.; NASCIMENTO, A.H.; ALBINO, L.F.T. Aminoácidos totais e digestíveis para aves. In: CONFERÊNCIA APINCO, 1999, Campinas. Anais... Campinas: Fundação Apinco de Ciência e Tecnologia Avícola, 1999. p.66.

SARTORI, J.R.; GONZALES, E.; MACARI, M. et al. Tipos de fibras musculares no músculo flexor do hálux de frangos de corte submetidos ao estresse pelo calor e frio e alimentados em “pair-feeding”. Revista Brasileira de Zootecnia, v.32, p.918925, 2003.

SILVA, E.C. Aspectos biomecânicos musculres relacionados à administração experimental de corticosteróide sistêmico. Ribeirão Preto: Universidade de São Paulo, 2002. 80p. Dissertação (Mestrado em Bioengenharia) - Universidade de São Paulo, 2002.

SUK, Y.O.; WASHBURN, K.W. Effects of environment on growth, efficiency of feed utilization, carcass fatness, and their association. Poultry Science, v.74, p.285-296, 1995.
TAKEARA, P.; TRINDADE NETO, M.A.; TOLEDO, A.L. et al. Níveis de lisina digestível para frangos de corte machos no período de 22 - 36 dias de idade. In: CONFERÊNCIA APINCO, 2005, Santos. Anais... Santos: Fundação Apinco de Ciência e Tecnologia Avícola, 2005. p.76.

UNIVERSIDADE FEDERAL DE VIÇOSA - UFV. Manual de utilização do programa (Sistemas de Análises Estatísticas e Genéticas - SAEG). (versão 8.0). Viçosa, MG: Universidade Federal de Viçosa, 2000. 150p.

VALERIO, S.R.; OLIVEIRA, R.F.M.; DONZELE, J.L. et al. Níveis de lisina digestível mantendo a relação entre lisina e demais aminoácidos essenciais para frangos de corte de 22 a 42 dias de idade, mantidos sob condições de frio. In: REUNIÃO ANUAL DA SOCIEDADE BRASILEIRA DE ZOOTECNIA, 38., 2001 Piacicaba. Anais... Piracicaba: Sociedade Brasileira de Zootecnia, 2001. (CD-ROM).

VALERIO, S.R.; OLIVEIRA, R.F.M.; DONZELE, J.L. et al. Níveis de lisina digestível em rações, em que se manteve ou não a relação aminoacídica, para frangos de corte de 22 a 42 dias de idade, mantidos em estresse por calor. Revista Brasileira de Zootecnia, v.32, p.372-382, 2003.

YUNIANTO, D.; HAYASHI, K.; KANEDA, S. et al. Effect of environmental temperature on muscle protein turnover and heat production in tube-fed broiler chickens. British Journal of Nutrition, v.77, p.878-909, 1997.

Recebido: 1/3/2007

Aprovado: 15/6/2007 